Article

\title{
Confidence in Government and Attitudes toward Bribery: A Country-Cluster Analysis of Demographic and Religiosity Perspectives
}

\author{
Serkan Benk ${ }^{1, *}$, Bahadır Yüzbaşı ${ }^{2}$ and Robert W. McGee ${ }^{3}$ \\ 1 Department of Public Finance, Inonu University, 44280 Malatya, Turkey \\ 2 Department of Econometrics, Inonu University, 44280 Malatya, Turkey; bahadir.yuzbasi@inonu.edu.tr \\ 3 School of Business and Economics, Fayetteville State University, 1200 Murchison Road Fayetteville, \\ NC 28301, USA; rmcgee3@uncfsu.edu \\ * Correspondence: serkan.benk@inonu.edu.tr
}

Academic Editor: Klaus Baumann

Received: 7 September 2016; Accepted: 5 January 2017; Published: 10 January 2017

\begin{abstract}
In this study, we try to classify the countries by the levels of confidence in government and attitudes toward accepting bribery by using the data of the sixth wave (2010-2014) of the World Values Survey (WVS). We are also interested in which demographic, attitudinal, and religiosity variables affect each class of countries. For these purposes cluster analysis, linear regression analysis, and ordered logistic regression analysis were used. The study found that countries could be grouped into two clusters which had varying levels of opposition to bribe taking and confidence in government. Another finding was that certain demographic, attitudinal, and religiosity variables that were significant in one cluster might not be significant in another cluster.
\end{abstract}

Keywords: ethics; religiosity; confidence in government; bribery; cluster analysis; linear regression; ordered logistic regression

\section{Introduction}

The general view is that bribery is always unethical. The Organisation for Economic Cooperation and Development [1] discourages the practice and several studies have viewed bribery negatively [2-8]. However, the issue is not as clear-cut as it might appear. For example, bribing a prison guard to release a political prisoner who is being held by a corrupt or evil regime might be an ethical act [9]. If one applies utilitarian ethical analysis, bribery would be acceptable in cases where there are more winners than losers (if total benefit exceeds total cost).

Before one can determine whether a particular bribe is ethical, or whether any bribe can be ethical, one must choose a set of ethical principles to apply to the situation. There are several ethical systems from which to choose, and not all ethical systems will yield the same result. Applying one set of ethical principles might lead one to conclude that a certain bribe is ethical while the application of another set of ethical principles might reach the opposite result. Baron, Pettit, and Slote identify and discuss three of the main ethical systems [10]. Graham discusses eight ethical systems [11]. Most ethical systems, when analyzed and closely compared, usually possess attributes of utilitarianism, rights theory, or virtue ethics, broadly defined.

Virtue ethics concludes that an act or policy is good if the result is human flourishing [12]. Utilitarian ethics holds that an act or policy is ethical if the result is the greatest good for the greatest number [13], or if the number of winners exceed the losers, or if the result is what economists call a positive-sum game [14-18]. Although these various utilitarian views are not quite the same, they are similar. If a policy and/or act results in human flourishing, it could meet both the virtue ethics test and 
the utilitarian ethics test. One branch of utilitarian ethics holds that something that increases efficiency is ethical $[19,20]$. This view has been criticized [17], yet it remains a mainstream utilitarian position.

Utilitarian ethics suffers from some structural flaws that need to be mentioned, although a full analysis of its flaws is beyond the scope of this paper. Luckily, these structural flaws have been addressed elsewhere [21,22].

One structural flaw is that it is impossible to precisely measure gains and losses. One may say that John prefers option A to option B, but one cannot say that he prefers option A to option B by 22.7 percent.

Another inherent flaw in utilitarian ethics is that it is not possible to even identify who the winners and losers are in many cases. Frédéric Bastiat pointed out this deficiency in the 1840s in his essay, What is Seen and What is Not Seen [23].

Even utilitarians cannot agree on the best definition of utilitarianism. Early utilitarians, including Mill and Bentham, referred to it as the greatest good for the greatest number [14,24]. The problem with this definition, aside from the fact that gains and losses cannot be measured and winners and losers often cannot be identified, is that it is mathematically impossible to maximize more than one variable at a time [17]. One may either strive for the greatest social good, or one may attempt to benefit the greatest number, but one cannot do both at the same time. Economists often use the term positive-sum game to identify a situation that meets the utilitarian requirement, but they seldom reveal whether they mean the greatest social benefit (which cannot be calculated) or merely whether the number of individuals who gain exceed the number who lose.

Another problem with the utilitarian calculus is that a particular act may benefit a few greatly while harming far more people only slightly. An example is protectionist trade legislation. Protectionism benefits a few producers (and their employees) a great deal, but harms perhaps millions of consumers a little [25]. Most economists agree that protectionist trade legislation results in a negative-sum game, meaning that overall losses exceed the gains, but it is impossible to arrive at a number that all economists can agree on.

Rights theory holds that an act is unethical if someone's rights are violated. Whether the winners exceed the losers is irrelevant $[10,14,17,26,27]$. One of the main criticisms of utilitarian ethics is that rights are disregarded. Taking a rights approach overcomes this deficiency in utilitarian ethics.

One may argue that this brief explanation is simplistic, but actually it is not, if one takes the position that 'real' rights (meaning negative rights instead of positive rights) do not conflict. For example, my right to swing my arms around ends where your nose begins. You have the right not to be punched in the nose, and I do not have the right to punch you in the nose.

Kantian ethics focuses on duty $[28,29]$. If someone breaches a duty, the act is considered to be unethical. The Kantian view may be applied to bribery in cases where the receiver of the bribe is an agent who has a duty to the principal to do what is in the best interest of the principal. An agent who acts against the best interest of the principal is acting unethically.

That being the case, one might reasonably ask about the ethics of a situation where the person accepting the bribe is not anyone's agent. In such cases, one may ask whether the individual receiving the bribe is offering anything extra in exchange for the bribe, or whether the person soliciting the bribe is merely abusing his/her power to obtain cash or other benefits in exchange for nothing. In other words, is it a helping hand bribe or a greedy hand bribe?

Most of the literature on ethical aspects of bribery does not cite philosophers or particular ethical theories, at least not directly. However, much of the literature has an underlying premise that either utilitarian ethics or principles of duty should be applied. Virtue ethics and rights theory also appear in some analyses, although most studies on bribery are done by economists or lawyers, who tend to be utilitarians, at least most of the time. Logue believes that bribery is always unethical because it violates absolute moral principles that cannot be compromised [30]. He states that bribery is basically unfair and results in an inefficient allocation of resources, and frustrates the constructive role of government. Logue's reasoning may be criticized on several counts. For example, bribes that grease the wheels of 
commerce can actually increase efficiency, as is discussed elsewhere in this paper. Also, as is discussed elsewhere in this paper, the helping hand kind of bribery might actually increase fairness.

Rawls discusses the concept of fairness [31]. The problem with the concept of fairness is that it is conveniently undefinable in a way that can be agreed upon by a majority of philosophers. Robert Nozick, another Harvard philosopher, wrote a book to specifically offer an alternative to Rawls [32].

Carson [33] argues that accepting a bribe is always prima facie wrong because it violates duties, but makes some exceptions, such as in cases of conscripted soldiers, some prostitutes and others who are held as virtual slaves. Johnsen applies cost-benefit analysis to determine whether paying a bribe results in a positive-sum game [34,35]. Shaw points out that benefits and costs cannot be easy to assess [36].

The aim of this paper is to contribute to the literature in three ways. Firstly, this study examines how the countries classify by the levels of confidence in government and attitudes toward accepting bribery by using the data of the sixth wave (2010-2014) of the World Values Survey (WVS). Secondly, the study examines if there is a relationship between attitude toward taking a bribe and the level of confidence in government. We thought there might be some correlation between confidence in government and attitude toward bribery, but we could not decide, a priori, what the relationship might be, so we decided to conduct a test to see what the correlation was, if any. While bribery by government officials is generally viewed negatively, it was not clear whether acceptance of bribery would be greater or less in cases where the confidence in government was either weak or strong. One might guess that bribery would be less acceptable in countries where confidence in government is high because bribery would tarnish the view of government in such cases. Alternatively, one might think that bribery would be more acceptable in countries where government officials are corrupt because bribery is a way to get around or circumvent impediments to doing business. Thus, examining the relationship between acceptance of bribery and confidence in government was thought to be a worthwhile venture. Finally, this study examines what kind of factors or variables affect the countries that have different levels of confidence in government and bribery attitudes.

It is necessary to raise the issue of ethical relativism at some point, and here seems to be as good a place as any. The theory of ethical relativism argues that what is ethical or unethical depends on one's culture, religion, and period of history. Human sacrifice used to be considered not only ethical but also required in some cultures. Polygamy is considered ethical in some cultures but not in others. Abortion, infanticide, female genital mutilation, suicide, the justifiability of killing humans or animals, tax evasion, and numerous other acts and practices could be mentioned. What is acceptable in one culture, religion, or time period may not be acceptable in another [37].

Providing a full discussion of this subject is beyond the scope of the present paper. However, it could fairly be said that cultural relativism might be a partial explanation for why the results of the present study are not identical for each country examined. In fact, it appears that there are at least three views presently accepted in the countries studied.

Because of the method in which the bribery question was asked, the parameters of the present study are limited. It was not possible to determine the reasoning behind the answers because participants were merely asked their opinion on whether bribery could be justified. No information was given that could hint at whether the participants applied utilitarian, rights, or Kantian theory. However, this lack of reasoning behind the responses also made the present study easier to conduct because we were able to focus on their responses without trying to analyze the reasoning behind them.

The remainder of the paper is structured as follows. First, the literature on confidence in government and attitudes toward bribery is analyzed. Second, the methodology of the empirical study and its main results are presented. Finally, the main contributions and limitations of the paper are discussed. 


\section{Literature Review}

Some scholars argue that bribery may serve a useful function if a bribe acts to grease the wheels of commerce, making commerce work more efficiently. Such would be the case where a corrupt government or inefficient bureaucracy can be bypassed by paying someone to cut red tape or alternatively go around the rules. Some works on this subject assert that, in general, bribery may be considered ethical if it is a helping hand, however, unethical when it is paid to a grabbing hand who offers nothing in return for the payment [38-40]. Wong and Beckman developed a point system to determine whether the helping hand or grabbing hand predominates [18].

Several researches have studied bribery in connection with other types of corruption, with a focus it has on foreign direct investment (FDI). Cuervo-Cazurra [3,4] and Mauro [41] assert that as a result of bribery FDI flows decreased, when in fact Egger and Winner point out that bribery acts to stimulate FDI in cases where it acts as a helping hand [39]. Weitzel and Berns found that host country corruption is negatively associated with premiums paid in cross-country mergers [42]. Sanyal and Samanta illustrate that bribery affects economic growth negatively [43].

Some researchers also examined individual attitudes toward accepting bribery with confidence in government. Presumably, one might assume that there is a relationship between attitude toward taking a bribe and the level of confidence in government. As confidence in government declines, one might expect that opposition to taking a bribe also declines. However, in related literature, this linear correlation appears to be always invalid. In literature, there are various studies which have examined the extent of confidence in government combined with ethical perspectives of bribery. For instance, it was not a significant variable in a comparative study which included the USA, Germany, and China [44]; in a study of three Latin American countries, namely Argentina, Brazil and Colombia [45]; and in an Australian study [46].

A comparative study for European countries found a linear relationship where those who placed a great deal of confidence in government opposed bribery more than those who placed little or no confidence in government [47]. A similar result was presented in a study of four Muslim countries. Nevertheless the relationship was not quite linear [48].

An African study revealed that those who placed no confidence in government were most opposed to taking a bribe while those with a great deal of confidence in government were the least opposed [49]. Another comparative study of the USA, Canada, and Mexico found that the two middle groups (those who had some confidence in government but not a great deal) showed the strongest opposition to bribe taking, whereas the two groups in the polar positions (least confidence and most confidence) showed the least opposition [50].

\section{Methodology}

\subsection{Data and Variables}

The data used in this study were taken from the most recent World Values Survey, which collected data from respondents in 60 countries between 2010 and 2014 in face-to-face interviews in the local languages with respondents over the age of 18 . The advantage of this survey is the wide set of variables relating to perceptions of social life, environment, work, family, politics and society, religion, ethics, and national identity. There are more Eastern, Western, and African countries participating in this wave which allows testing the generalizability of previous findings. The last wave also includes countries from very different social, religious, and cultural backgrounds. In addition, the WVS collects basic information including public attitudes towards bribery. The present study analyzes the data reflecting individual attitudes toward bribery and confidence in government. Table 1 lists the countries and sample sizes of the data.

In this study, we consider the two dependent variables: attitudes towards bribery and confidence in government. The first dependent variable of individual attitudes toward bribery was measured by the item "Someone accepting a bribe in the course of their duties." A 10-point Likert Scale was used, 
where $1=$ never justifiable and $10=$ always justifiable (Question number is V202 in WVS). The second independent variable of confidence in government was measured by the item "How do you trust in the government (in your nation's capital)?" with a 4-point Likert Scale was used, where $1=$ not at all and $4=$ a great deal (Question number is V115 in WVS).

Table 1. List of the Countries.

\begin{tabular}{ccccccccc}
\hline Code & Country & $\mathbf{N}$ & Code & Country & $\mathbf{N}$ & Code & Country & N \\
\hline DZ & Algeria & 1200 & IND & India & 1581 & Q & Qatar & 1060 \\
AZ & Azerbaijan & 1002 & IRQ & Iraq & 1200 & RO & Romania & 1503 \\
RA & Argentina & 1030 & J & Japan & 2443 & RUS & Russia & 2500 \\
AUS & Australia & 1477 & KZ & Kazakhstan & 1500 & RWA & Rwanda & 1527 \\
BRN & Bahrain & 1200 & HKJ & Jordan & 1200 & SGP & Singapore & 1972 \\
AM & Armenia & 1100 & ROK & South Korea & 1200 & SLO & Slovenia & 1069 \\
BR & Brazil & 1486 & KWT & Kuwait & 1303 & ZA & South Africa & 3531 \\
BY & Belarus & 1535 & KS & Kyrgyzstan & 1500 & ZW & Zimbabwe & 1500 \\
RCH & Chile & 1000 & RL & Lebanon & 1200 & E & Spain & 1189 \\
CHN & China & 2300 & LAR & Libya & 2131 & S & Sweden & 1206 \\
RC & Taiwan & 1238 & MAL & Malaysia & 1300 & T & Thailand & 1200 \\
CO & Colombia & 1512 & MEX & Mexico & 2000 & TT & Trinidad and Tobago & 999 \\
CY & Cyprus & 1000 & MA & Morocco & 1200 & TN & Tunisia & 1205 \\
EC & Ecuador & 1202 & NL & Netherlands & 1902 & TR & Turkey & 1605 \\
EST & Estonia & 1533 & NZ & New Zealand & 841 & UA & Ukraine & 1500 \\
GE & Georgia & 1202 & WAN & Nigeria & 1759 & ET & Egypt & 1523 \\
PS & Palestine & 1000 & PK & Pakistan & 1200 & USA & United States & 2232 \\
D & Germany & 2046 & PE & Peru & 1210 & UY & Uruguay & 1000 \\
GH & Ghana & 1552 & RP & Philippines & 1200 & UZ & Uzbekistan & 1500 \\
HK & Hong Kong & 1000 & PL & Poland & 966 & YAR & Yemen & 1000 \\
\hline
\end{tabular}

In this paper, there were also several variables contained as independent variables. These independent variables were categorized into three groups: demographic, attitudinal, and religiosity variables. The independent variables detailed in Table 2.

Table 2. Independent Variable Questions from World Values Survey (wave 6).

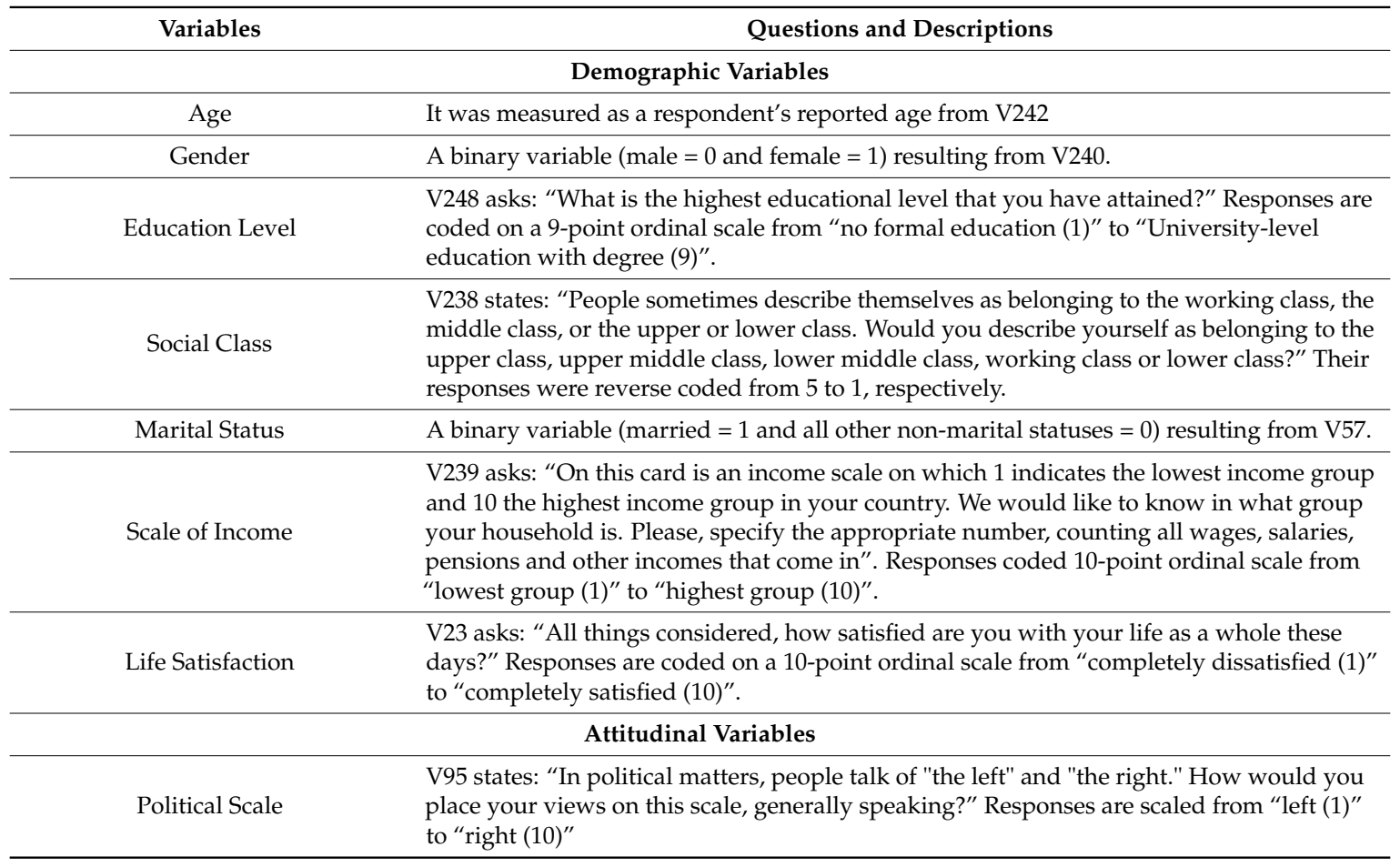


Table 2. Cont.

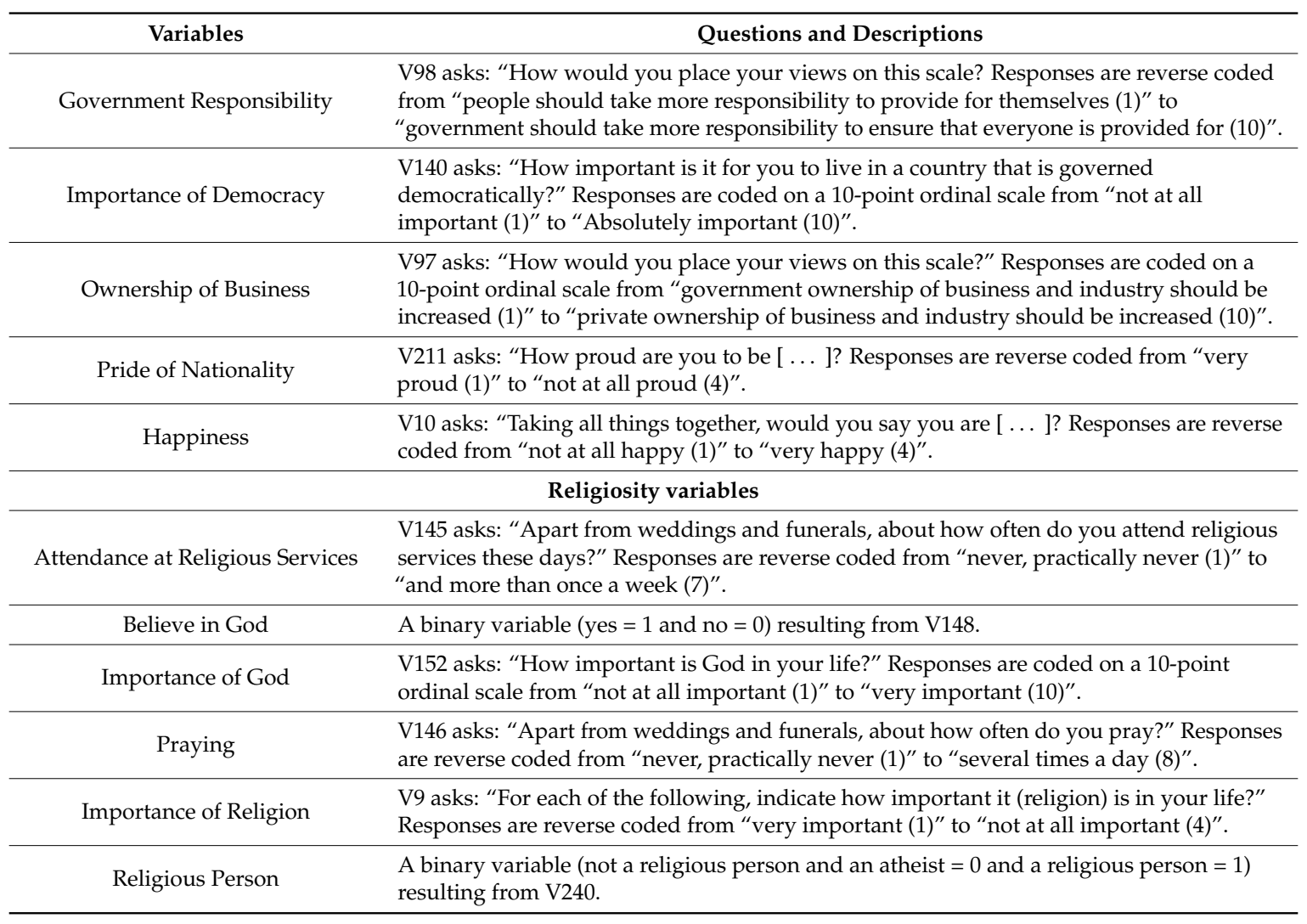

\subsection{ClusterAnalysis}

In order to see how the countries classify by the levels of confidence in government and attitudes toward accepting bribery, a cluster analysis was conducted. All analyses were performed in R statistical software [51].

According to the observations for each of 60 countries examined by us, the means level of confidence in government and bribery attitudes were calculated. We created the scatter diagram (see Figure 1). Uzbekistan (UZ), Qatar (Q), Azerbaijan (AZ), China (CHN), India (IND), Philippines (RP), Lebanon (RL), and South Africa (ZA) are different from the other countries obviously. It does not make sense to examine the cluster, which consists of a small number of elements. Therefore, we removed the observations for these countries from further analysis.

In order to generate clusters of approximately equal size we used hclust function in stats package in R for Hierarchical Clustering Analysis via Ward's method (see in Figure 2). For the more precise analysis we used the k-means clustering analysis, which is obtained from kmeans function in stats package in R. We also indicate that for it is used the Euclidean distance between observations and centers of clusters for both methods. We have also used NbClust function in NbClust package for determining the best numbers of clusters [52]. For k-means cluster analysis, the 10 of 26 criteria suggest a two-cluster solution (see Figure 3). Again Hierarchical Clustering Analysis, the Nbclust function suggests a two-cluster solution. 


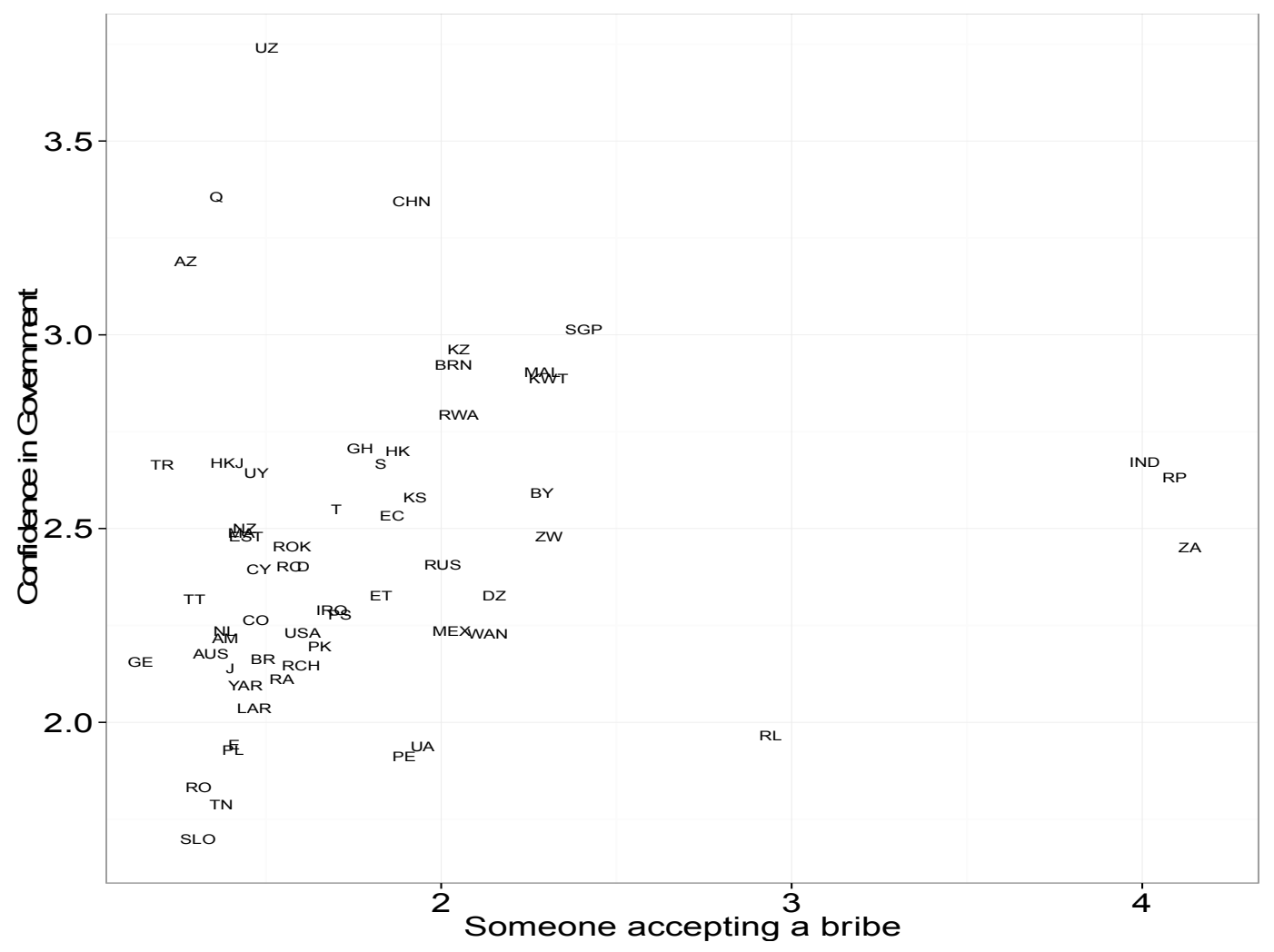

Figure 1. Scatter Diagram.

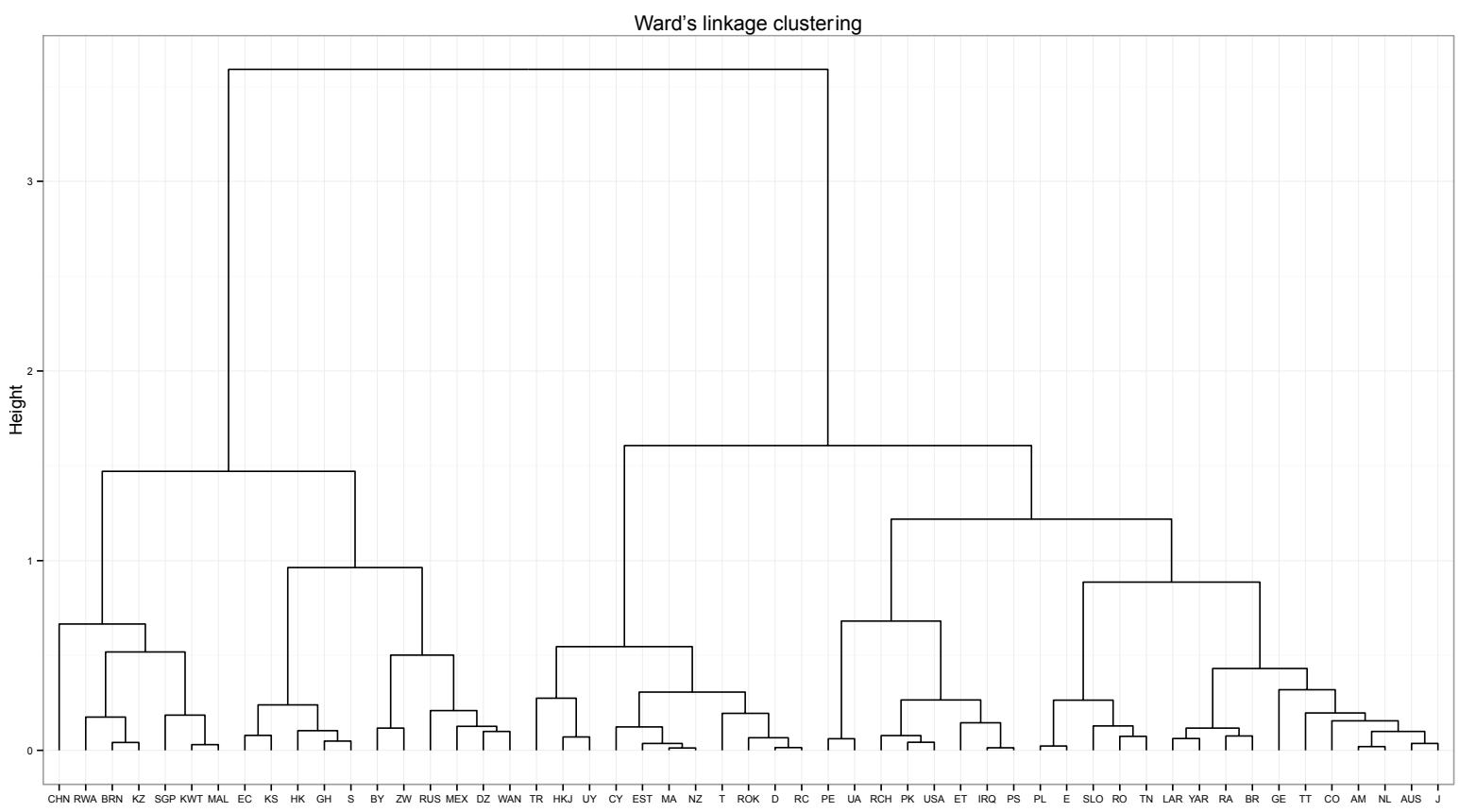

Figure 2. Ward's Dendrogram. 


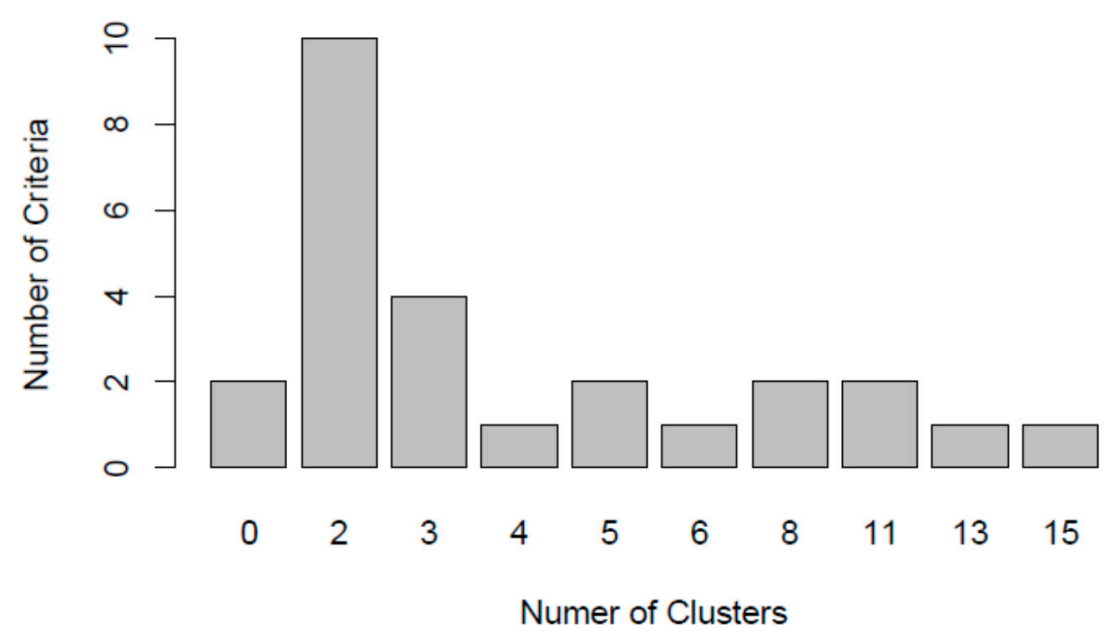

Figure 3. Number of clusters chosen by 26 criteria.

After the visual segmentation of the countries we determined the centers of each cluster: Brazil (Cluster 1) and Rwanda (Cluster 2). As a result, the objects fall within the cluster, the distance to the center of which is minimal. Thus we obtain two groups of the countries according to the level of bribery acceptability and the level of confidence in government (see in Figures 4 and 5).
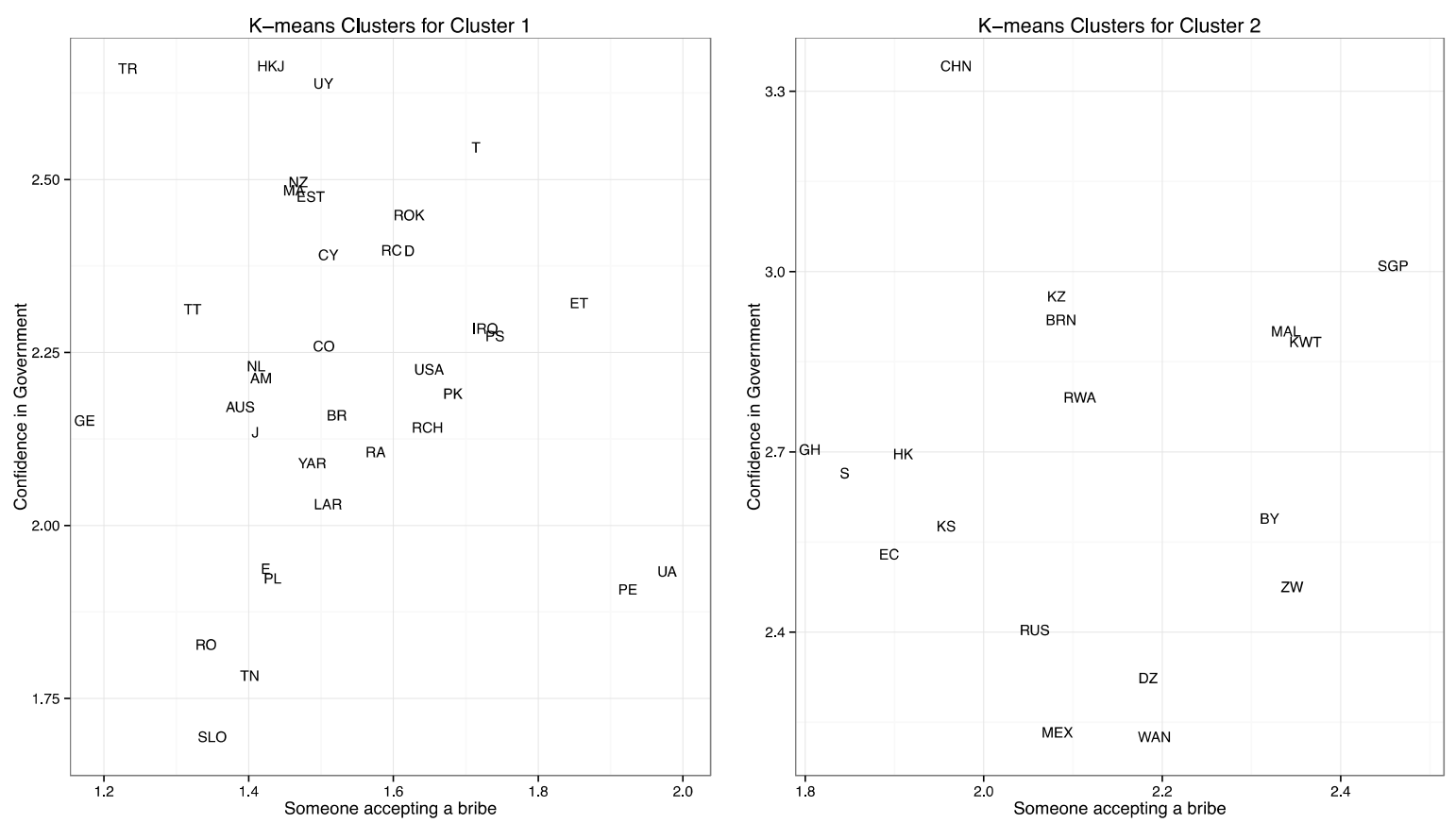

Figure 4. Cluster 1 and Cluster 2. 

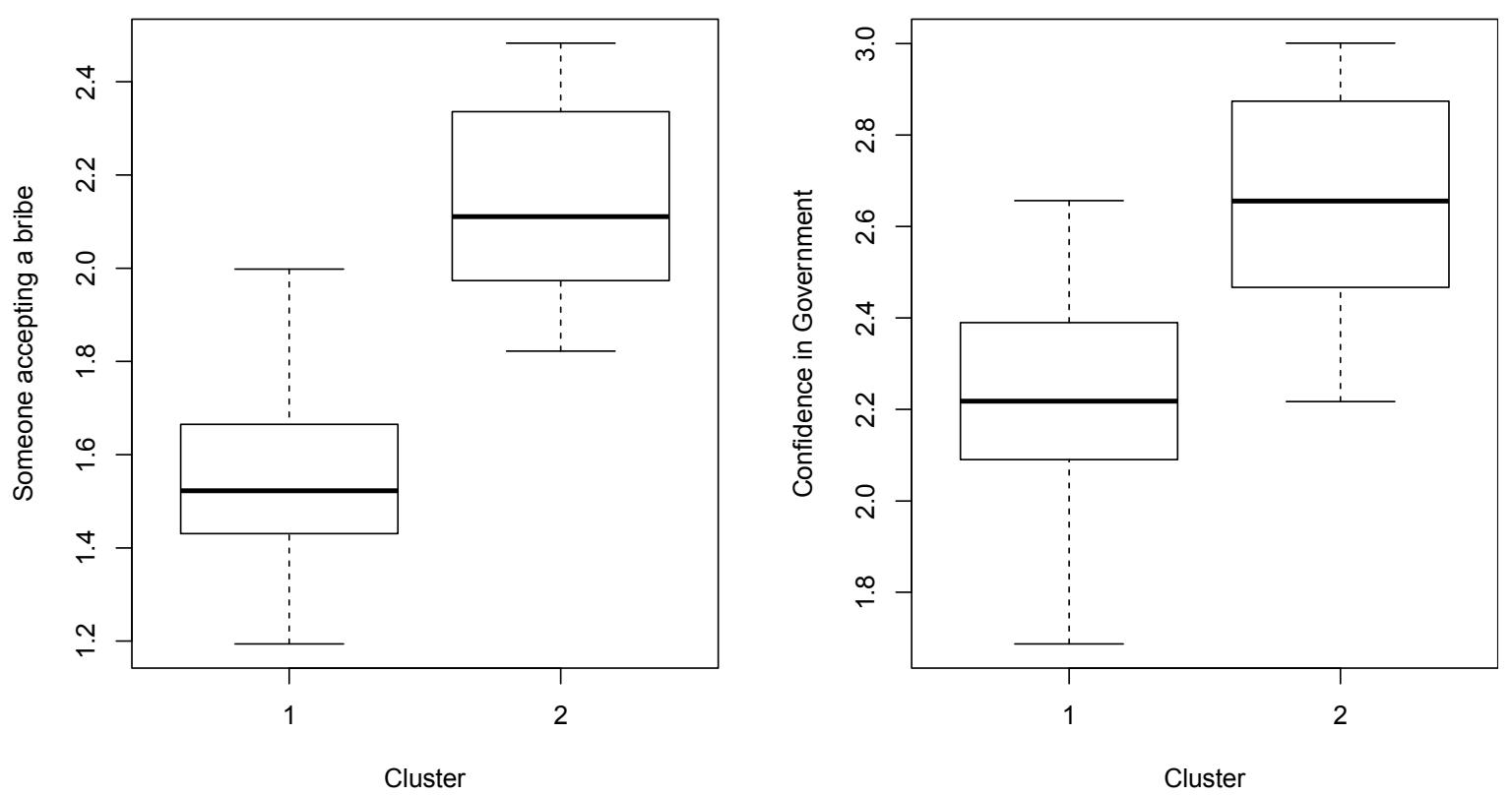

Figure 5. Box plot of Cluster Analysis.

As you can see from Figure 4, Cluster $1(\mathrm{~N}=50484)$ contains the countries of whose respondents have low level of bribery acceptability (mean 1.54) and low level of confidence in government (mean 2.21) (see in Figure 5). This cluster also contains completely different countries of the world (Australia, United States, South Korea, Germany), and the poor ones (Pakistan, Yemen, Armenia).

Cluster $2(\mathrm{~N}=25451)$, see Figure 4, contains the countries whose respondents have a high level of bribery acceptability (mean 2.13) and a high level of confidence in government (mean 2.67). With the exception of Hong Kong, Singapore, and Sweden most of the countries in this cluster were either developing countries (Algeria, Ecuador, Ghana, Malaysia, Mexico, etc.) or countries in the process of transition from central planning to a market economy (Russia, Kazakhstan, Kyrgyzstan, and Belarus). The details' of the Cluster 1 and Cluster 2 countries are shown in Table 3. 
Table 3. Clusters of Countries.

\begin{tabular}{|c|c|c|c|c|c|c|c|c|c|c|c|}
\hline Code & $\begin{array}{l}\text { Bribery } \\
\text { Mean }\end{array}$ & $\begin{array}{c}\text { Confidence } \\
\text { Mean }\end{array}$ & Cluster & Code & $\begin{array}{l}\text { Bribery } \\
\text { Mean }\end{array}$ & $\begin{array}{c}\text { Confidence } \\
\text { Mean }\end{array}$ & Cluster & Code & $\begin{array}{c}\text { Bribery } \\
\text { Mean }\end{array}$ & $\begin{array}{c}\text { Confidence } \\
\text { Mean }\end{array}$ & Cluster \\
\hline RA & 1.59 & 2.09 & 1 & PE & 1.94 & 1.89 & 1 & SGP & 2.48 & 3.00 & 2 \\
\hline $\mathrm{AM}$ & 1.43 & 2.20 & 1 & PL & 1.45 & 1.95 & 1 & $\mathrm{ZW}$ & 2.36 & 2.46 & 2 \\
\hline AUS & 1.41 & 2.16 & 1 & $\mathrm{RO}$ & 1.36 & 1.82 & 1 & $\mathrm{GH}$ & 1.82 & 2.69 & 2 \\
\hline $\mathrm{BR}$ & 1.54 & 2.15 & 1 & SLO & 1.37 & 1.68 & 1 & RUS & 2.08 & 2.39 & 2 \\
\hline $\mathrm{CO}$ & 1.52 & 2.25 & 1 & ROK & 1.65 & 2.44 & 1 & MAL & 2.36 & 2.89 & 2 \\
\hline $\mathrm{CY}$ & 1.52 & 2.38 & 1 & E & 1.43 & 1.92 & 1 & S & 1.85 & 2.65 & 2 \\
\hline $\mathrm{RCH}$ & 1.67 & 2.13 & 1 & $\mathrm{RC}$ & 1.61 & 2.39 & 1 & WAN & 2.21 & 2.21 & 2 \\
\hline ET & 1.87 & 2.31 & 1 & $\mathrm{~T}$ & 1.72 & 2.53 & 1 & RWA & 2.13 & 2.78 & 2 \\
\hline EST & 1.51 & 2.46 & 1 & $\mathrm{TT}$ & 1.33 & 2.30 & 1 & HK & 1.92 & 2.68 & 2 \\
\hline GE & 1.19 & 2.14 & 1 & $\mathrm{TN}$ & 1.42 & 1.77 & 1 & $\mathrm{DZ}$ & 2.19 & 2.31 & 2 \\
\hline $\mathrm{D}$ & 1.63 & 2.38 & 1 & $\mathrm{TR}$ & 1.25 & 2.65 & 1 & KS & 1.97 & 2.56 & 2 \\
\hline IRQ & 1.75 & 2.27 & 1 & UA & 1.99 & 1.92 & 1 & BRN & 2.11 & 2.91 & 2 \\
\hline $\mathrm{J}$ & 1.41 & 2.12 & 1 & USA & 1.67 & 2.17 & 1 & $\mathrm{KZ}$ & 2.09 & 2.95 & 2 \\
\hline HKJ & 1.45 & 2.65 & 1 & UY & 1.52 & 2.63 & 1 & $\mathrm{EC}$ & 1.90 & 2.52 & 2 \\
\hline LAR & 1.53 & 2.02 & 1 & YAR & 1.51 & 2.08 & 1 & MEX & 2.10 & 2.22 & 2 \\
\hline MA & 1.48 & 2.47 & 1 & PS & 1.75 & 2.26 & 1 & KWT & 2.38 & 2.87 & 2 \\
\hline NL & 1.42 & 2.22 & 1 & PK & 1.70 & 2.18 & 1 & BY & 2.33 & 2.58 & 2 \\
\hline NZ & 1.48 & 2.48 & 1 & & & & & & & & \\
\hline
\end{tabular}




\section{Results}

For a better understanding of the determinants concerning the attitude of the respondents to accepting bribery and confidence in government, we ran a series of regression models for each cluster. Firstly, we conducted a linear regression model for bribery attitudes. The results of the linear regression model's estimation are summarized in Table 4.

Table 4. Linear regression results of the clusters: Attitudes towards accepting bribery.

\begin{tabular}{|c|c|c|c|c|c|c|}
\hline \multirow{2}{*}{ Variables } & \multicolumn{3}{|c|}{ Cluster 1} & \multicolumn{3}{|c|}{ Cluster 2} \\
\hline & $\beta$ & Std. Err. & $p$-Value & $\beta$ & Std. Err. & $p$-Value \\
\hline \multicolumn{7}{|l|}{ Demographic Variables } \\
\hline Age & -0.014 & 0.001 & $0.000^{* *}$ & -0.005 & 0.001 & $0.000 * *$ \\
\hline Gender (Female $=1$ ) & -0.113 & 0.022 & $0.000 * *$ & -0.111 & 0.034 & $0.001^{* *}$ \\
\hline Education Level & -0.062 & 0.005 & $0.000 * *$ & -0.024 & 0.008 & $0.002 * *$ \\
\hline Social Class & -0.024 & 0.012 & $0.048 *$ & 0.047 & 0.019 & $0.015 *$ \\
\hline Marital Status (Married=1) & 0.173 & 0.023 & $0.000 * *$ & 0.045 & 0.036 & 0.211 \\
\hline Scale of Income & 0.088 & 0.006 & $0.000^{* *}$ & 0.004 & 0.009 & 0.691 \\
\hline Life Satisfaction & -0.067 & 0.006 & $0000^{* *}$ & -0.015 & 0.009 & 0.077 \\
\hline \multicolumn{7}{|l|}{ Attitudinal Variables } \\
\hline Political Scale & 0.035 & 0.005 & $0.000 * *$ & 0.064 & 0.008 & $0.000^{* *}$ \\
\hline Government Responsibility & 0.062 & 0.004 & $0.000 * *$ & 0.041 & 0.006 & $0.000^{* *}$ \\
\hline Importance of Democracy & -0.141 & 0.005 & $0.000 * *$ & -0.085 & 0.009 & $0.000 * *$ \\
\hline Confidence in Government & 0.094 & 0.012 & $0.000^{* *}$ & 0.010 & 0.019 & 0.591 \\
\hline Ownership of Business & 0.021 & 0.004 & $0.000 * *$ & 0.033 & 0.006 & $0.000^{* *}$ \\
\hline Pride of Nationality & -0.067 & 0.014 & $0.000 * *$ & -0.125 & 0.025 & $0.000 * *$ \\
\hline Happiness & 0.024 & 0.017 & 0.169 & -0.023 & 0.027 & 0.406 \\
\hline \multicolumn{7}{|l|}{ Religiosity Variables } \\
\hline Attendance at Religious Services & 0.055 & 0.007 & $0.000 * *$ & 0.035 & 0.011 & $0.002 * *$ \\
\hline Believe in God (Yes $=1$ ) & -0.320 & 0.042 & $0.000 * *$ & -0.146 & 0.078 & 0.062 \\
\hline Importance of God & -0.099 & 0.006 & $0.000 * *$ & -0.043 & 0.009 & 0.000 \\
\hline Praying & 0.005 & 0.007 & 0.462 & 0.036 & 0.010 & $0.000^{* *}$ \\
\hline Importance of Religion & 0.035 & 0.015 & $0.021 *$ & 0.079 & 0.022 & $0.000 * *$ \\
\hline \multirow[t]{2}{*}{ Religious person (Religious Person $=1$ ) } & -0.143 & 0.030 & $0.000 * *$ & -0.133 & 0.049 & $0.006^{* *}$ \\
\hline & \multicolumn{3}{|c|}{$\begin{array}{l}\mathrm{R}^{2}=0.082 \text { Adj. } \mathrm{R}^{2}=0.082 \\
\mathrm{~F}(18,32,531) p<0.000\end{array}$} & \multicolumn{3}{|c|}{$\begin{array}{l}\mathrm{R}^{2}=0.038 \text { Adj. } \mathbf{R}^{2}=0.037 \\
\mathrm{~F}(19,14,085) p<0.000\end{array}$} \\
\hline
\end{tabular}

The first column in Table 4 presented the results of explanatory variables in predicting Cluster 1 respondents' attitudes toward accepting a bribe. Eighteen variables-age, gender, education level, social class, marital status, scale of income, life satisfaction, political scale, government responsibility, importance of democracy, confidence in government, ownership of business, pride of nationality, attendance at religious services, believe in god, importance of God, importance of religion, and religious person were significantly associated with the attitudes towards accepting bribery. The following characteristics are associated with greater beliefs that bribery is never justified: the elderly, females, respondents who are well-educated, respondents with a higher social class and a higher score of life satisfaction, respondents with a higher score of importance of democracy and pride of nationality, importance of God, believe in God, and the more religious people. Eight characteristics are associated with lower beliefs that bribery is never justified: respondents who are married, respondents with a higher scale of income, the right side of the political scale, encourage that private ownership of business and industry should be increased and the higher score of government responsibility, higher score of confidence in government, higher scores of attendance at religious services and importance of religion.

The second column in Table 4 shows the results of explanatory variables in predicting Cluster 2 respondents' attitudes toward accepting a bribe. Thirteen variables-age, gender, education level, social class, political scale, government responsibility, importance of democracy, ownership of business, 
pride of nationality, attendance at religious services, praying, importance of religion, and religious person were significantly associated with the attitudes towards accepting bribery. The following characteristics are associated with greater beliefs that bribery is never justified: the elderly, females, respondents who are well-educated, the higher score of importance of democracy, the higher score of pride of nationality, and the more religious people. Seven characteristics are associated with lower beliefs that bribery is never justified: respondents in a higher social class, respondents on the right side of the political scale, encourage that private ownership of business and industry should be increased and the higher score of government responsibility, respondents with the higher scores of attendance at religious services, respondents with the higher score of importance of religion and praying.

We also conducted an ordered regression model to identify the factors influencing the respondents' confidence in government for each cluster. The results of the ordered regression models estimation are summarized in Table 5. The first column in this table showed the results of the explanatory variables in predicting of Cluster 1. Fifteen variables-age, gender, social class, scale of income life satisfaction, political scale, government responsibility, importance of democracy, ownership of business, pride of nationality, attitudes toward bribery, happiness, attendance at religious services, importance of God, and importance of religion were significantly associated with the level of confidence in government. The following characteristics are positively affected by the level of confidence in government: the elderly, respondents in a higher social class, higher score of life satisfaction and scale of income, respondents on the right side of political scale, a higher score of importance of democracy and a higher score of pride of nationality, respondents who encourage that private ownership of business and industry should be increased, respondents with a higher score of pride of nationality, respondents with a lower belief that bribery is never justified, respondents with a high score of happiness, respondents with the higher scores of attendance at religious services and importance of religion. Only two variables are negatively correlated with the level confidence in government: females and respondents who express the belief that God is important in their life.

Table 5. Ordered logistic regression results of the clusters: Confidence in government.

\begin{tabular}{|c|c|c|c|c|c|c|}
\hline \multirow{2}{*}{ Variables } & \multicolumn{3}{|c|}{ Cluster 1} & \multicolumn{3}{|c|}{ Cluster 2} \\
\hline & $\beta$ & Std. Err. & $p$-Value & $\beta$ & Std. Err. & $p$-Value \\
\hline \multicolumn{7}{|l|}{ Demographic Variables } \\
\hline Gender (Female =1) & -0.073 & 0.021 & $0.000 * *$ & -0.076 & 0.032 & $0.018 *$ \\
\hline Education Level & 0.000 & 0.005 & 0.961 & 0.004 & 0.007 & 0.575 \\
\hline Scale of Income & 0.036 & 0.006 & $0.000 * *$ & 0.017 & 0.009 & 0.060 \\
\hline Life Satisfaction & 0.022 & 0.005 & $0.000^{* *}$ & 0.007 & 0.008 & 0.377 \\
\hline \multicolumn{7}{|l|}{ Attitudinal Variables } \\
\hline Political Scale & 0.059 & 0.005 & $0.000 * *$ & 0.046 & 0.007 & $0.000 * *$ \\
\hline Government Responsibility & 0.024 & 0.004 & $0.000 * *$ & -0.007 & 0.006 & 0.214 \\
\hline Happiness & 0.135 & 0.016 & $0.000^{* *}$ & 0.109 & 0.026 & $0.000^{* *}$ \\
\hline \multicolumn{7}{|l|}{ Religiosity Variables } \\
\hline Attendance at Religious Services & 0.018 & 0.007 & $0.007^{*}$ & 0.015 & 0.010 & 0.139 \\
\hline Believe in God (Yes=1) & -0.045 & 0.040 & 0.254 & 0.319 & 0.074 & $0.000 * *$ \\
\hline Importance of God & -0.044 & 0.005 & $0.000 * *$ & 0.033 & 0.008 & $0.000 * *$ \\
\hline Praying & -0.010 & 0.006 & 0.125 & -0.082 & 0.009 & $0.000 * *$ \\
\hline Importance of Religion & 0.105 & 0.014 & $0.000 * *$ & 0.119 & 0.021 & $0.000 * *$ \\
\hline Religious Person (Religious Person=1) & -0.060 & 0.028 & 0.031 & -0.163 & 0.046 & $0.000 * *$ \\
\hline $\mathrm{R}^{2}$ (Nagelkerke) & 0.049 & & & 0.049 & & \\
\hline $\mathrm{R}^{2}$ (Cox \& Snell) & 0.045 & & & 0.045 & & \\
\hline
\end{tabular}


The second column in Table 5 presents the results of the explanatory variables in predicting the results of Cluster 2. Eleven variables-gender, marital status, political scale, importance of democracy, pride of nationality, happiness, believe in God, importance of God, praying, importance of religion, and religious person were significantly associated with the level confidence in government. The following characteristics are positively correlated with the level of confidence in government: respondents who are married, respondents on the right side of the political scale, respondents with higher score for importance of democracy and pride of nationality, respondents with a high score for happiness, respondents who believe in God, respondents who express the importance of God and religion. Three variables are negatively correlated with the level of confidence in government: females, respondents who encourage that private ownership of business and industry should be increased, and respondents with a high score of praying.

\section{Conclusions}

Our research found several interesting facts. Opinions on the ethics of accepting a bribe in the course of business differ. Opinions can be significantly different in different countries. Certain demographic variables are also significant. Comparing results between and among countries found that opinions can be categorized into several clusters, although some countries did not fit in either of the clusters we uncovered. Variables that are significant in one cluster may not be significant in another cluster.

There is a relationship between confidence in government and a person's view of bribery. Actually, we discovered two conflicting relationships. The people who live in rich or poor countries tend to have a low opinion of both bribery and government. People in developing and transition countries tend to have a more positive view of bribery acceptability and a higher confidence level in government.

One interesting question that could be raised is "Why are some variables significant whereas other variables are not?" One possible answer might be that some demographic variables are more sensitive to cultural or religious differences whereas others are not. This explanation might lead one to conclude that ethics is more relative in some cases than others. Some ethical concepts and beliefs are similar across a wide range of cultures and historical periods, whereas others are more amenable to change. Perhaps there are other explanations as well. Future studies could shed more light on possible answers to this question.

Another question that might be raised is "What do the findings of this study tell us about democracy?" Finding an answer to this question is difficult for several reasons. For one, not all countries included in the present study are democracies. Also, there are wide variations even among the countries that are democracies. Thus, it is impossible to make any generalizations about the relationship between democracy and views toward bribery. Some countries that either are not democracies or that are weak democracies might have a higher degree of confidence in their government than countries that have a strong democracy that is corrupt. One or more future studies are planned to explore the relationship between democracy (or theocracy or dictatorship) and views toward bribery.

The findings in the present study are basically consistent with those of the various Hernandez and McGee studies [44-50]. In those studies, some variables were significant while others were not, and some correlations were positive while others were negative. Some variables were significant in some studies but not in others. However, the present study goes beyond the Hernandez and McGee studies by examining additional variables and many more countries.

This study makes several contributions to the literature. The mere size and diversity of the sample-85,000 respondents from 60 countries-makes it one of the largest studies, if not the largest study on the issue of views toward bribery. The study was able to identify differences in views based on several demographic variables, lending some credibility to the view that ethics is at least sometimes relative.

The Hernandez and McGee studies examined only a few countries [44-50], whereas the present study examined 60 countries. The Hernandez and McGee studies used the Wave 5 World Values 
Survey data, which conducted surveys between 2005 and 2009, whereas the present study uses the most current (Wave 6) data, which are from surveys conducted between 2010 and 2014. The present study also included a few variables the Hernandez and McGee studies did not include.

The present research identifies areas in further need of examination. Future surveys could delve into the reasons behind the various answers. Additionally, other demographic variables could be examined to determine whether such variables make a difference in the various countries and cultures. Surveys could be conducted in other countries that are not included in the present study. The Hernandez and McGee studies included a longitudinal analysis to determine whether views toward bribery have changed over time. The present study did not perform that analysis because of time and space constraints.

The main weakness in this study was the fact that respondents' reasons for their views on the various questions were not solicited. Such an oversight is understandable, given the fact that the survey instrument included hundreds of questions and dozens of demographic, attitudinal, and other variables. Discussing reasons for each response would have been overly burdensome. However, it would be possible to delve into the reasons for the various responses in future studies that focused on just one or a few of the questions that were included in the WVS survey. Such an approach could be very fruitful for future research projects.

Another fruitful path for future research would be to conduct longitudinal studies for those countries where the bribery question was included in prior World Values Surveys. Such studies would reveal whether views on bribery have changed over the years, although they would not reveal the reasons for the changes. Obtaining the reasons for the changes in attitudes would require additional studies.

Author Contributions: Serkan Benk and Bahadır Yüzbaşı designed the study and conducted statistical analysis. Robert W. McGee and Serkan Benk contributed to the analysis and writing.

Conflicts of Interest: The authors declare no conflict of interest.

\section{References}

1. Organization for Economic Co-Operation and Development (OECD). Convention on Combating Bribery of Foreign Public Officials in International Business Transactions and Related Documents. Paris: OECD, 2011.

2. Nicola Bonucci, and Patrick Moulette. "The OECD Anti-Bribery Convention 10 years on." The OECD Observer, December 2007.

3. Alvaro Cuervo-Cazurra. “Who cares about corruption?" Journal of International Business Studies 37 (2006): 807-22. [CrossRef]

4. Alvaro Cuervo-Cazurra. "The effectiveness of laws against bribery abroad." Journal of International Business Studies 39 (2008): 634-51. [CrossRef]

5. Masako N. Darrough. "The FCPA and the OECD convention: Some lessons from the US experience." Journal of Business Ethics 93 (2010): 255-76. [CrossRef]

6. Jon Moran. "Bribery and corruption: The OECD Convention on combating the bribery of foreign public officials in international business transactions." Business Ethics: A European Review 8 (1999): 141-50. [CrossRef]

7. Carl Pacini, Judyth A. Swingen, and Hudson Rogers. "The role of the OECD and EU Conventions in combating bribery of foreign public officials." Journal of Business Ethics 37 (2002): 385-405. [CrossRef]

8. S. Scharf. "Few governments enforce foreign bribery prohibition." Internal Auditor 65 (2008): 14-16.

9. Achinto Roy, and Alan E. Singer. "Reducing corruption in international business: Behavioural, managerial and political approaches." Journal of Economic and Social Policy 10 (2006): 1-18.

10. Marcia Baron, Philip Pettit, and Michael Slote. Three Methods of Ethics. Malden: Blackwell Publishing; Oxford: Blackwell Publishing, 1997.

11. Gibson Graham. Eight Methods of Ethics. London: Routledge. New York: Routledge, 2004.

12. Aristotle. Nichomachean Ethics. Oxford: Oxford University Press, 2002.

13. Manuel G. Velasquez. Business Ethics: Concepts and Cases, 7th ed. Upper Saddle River: Pearson, 2011.

14. Richard B. Brandt. Morality, Utilitarianism, and Rights. Victoria. Cambridge: Cambridge University Press, 1992. 
15. Raymond Gillespie Frey, ed. Utility and Rights. Minneapolis: University of Minnesota Press, 1984.

16. Robert E. Goodin. Utilitarianism as a Public Philosophy. Cambridge: Cambridge University Press, 1995.

17. Robert W. McGee. "Property Rights v. Utilitarian Ethics." In Handbook of the Philosophical Foundations of Business Ethics. Edited by Christoph Lütge. Dordrecht: Springer, 2012, pp. 1263-74.

18. Alan Wong, and Eugene Beckman. "An applied ethical analysis system in business." Journal of Business Ethics 11 (1992): 173-78. [CrossRef]

19. Richard A. Posner. The Economics of Justice. Cambridge: Harvard University Press, 1983.

20. Richard A. Posner. Economic Analysis of Law, 5th ed. New York: Aspen Law \& Business, 1998.

21. Robert W. McGee. "The Fatal Flaw in the Methodology of Law \& Economics." Commentaries on Law $\mathcal{E}$ Economics 1 (1997): 209-23.

22. Murray N. Rothbard. Man, Economy and State. Los Angeles: Nash Publishing, 1970, pp. 160-68.

23. Frédéric Bastiat. "What is Seen and what is not Seen." In FrédéricBastiat, Selected Essays on Political Economy. Irvington-on-Hudson: Foundation for Economic Education, 1995.

24. John Stuart Mill. “Utilitarianism." Available online: http://www.earlymoderntexts.com/assets/pdfs/ mill1863.pdf (accessed on 20 December 2016).

25. Robert W. McGee. "The Fatal Flaw in NAFTA, GATT and All Other Trade Agreements. Northwestern." Journal of International LawE Business 14 (1994): 549-65.

26. Robert W. McGee. "The Body as Property Doctrine." In Handbook of the Philosophical Foundations of Business Ethics. Edited by Christoph Lütge. Dordrecht: Springer, 2012, pp. 1275-304.

27. Robert W. McGee. "Property Rights v. Governments." In Handbook of the Philosophical Foundations of Business Ethics. Edited by Christoph Lütge. Dordrecht: Springer, 2012, pp. 1305-23.

28. Immanuel Kant. "Fundamental Principles of the Metaphysics of Morals." In Great Books of the Western World. Chicago: Encyclopedia Britannica, 1952, vol. 42, pp. 251-87.

29. Immanuel Kant. Ethical Philosophy. Indianapolis: Hackett Publishing Company. Cambridge: Hackett Publishing Company, 1983.

30. Niles C. Logue. “Cultural Relativism or Ethical Imperialism? Dealing with Bribery across Cultures." In Paper presented at CBFA Conference, San Diego, California, USA, 13-15 October 2005.

31. John Rawls. A Theory of Justice. Boston: Belknap Press, 1971.

32. Robert Nozick. Anarchy, State and Utopia. New York: Basic Books, 1974.

33. Thomas L. Carson. "Bribery and Implicit Agreements: A Reply to Philips." Journal of Business Ethics 4 (1987): 249-51. [CrossRef]

34. D. Bruce Johnsen. "'The Ethics of "Commercial Bribery': Integrative Social Contract Theory Meets Transaction Cost Economics." Journal of Business Ethics 88 (2009): 791-803. [CrossRef]

35. D. Bruce Johnsen. "Mutual Funds." In Finance Ethics: Critical Issues in Theory and Practice. Edited by John R. Boatright. Hoboken: John Wiley \& Sons, 2010.

36. Bill Shaw. "Foreign Corrupt Practices Act: A Legal and Moral Analysis." Journal of Business Ethics 7 (1988): 789-95. [CrossRef]

37. Steven Lukes. Moral Relativism. New York: Picador, 2008.

38. Enrico Colombatto. "Why is corruption tolerated?" The Review of Austrian Economics 16 (2003): 363-79. [CrossRef]

39. Peter Egger, and Hannes Winner. "Evidence on corruption as an incentive for foreign direct investment." European Journal of Political Economy 21 (2005): 932-52. [CrossRef]

40. Douglas A. Houston. "Can corruption ever improve and economy." Cato Journal 27 (2007): 325-42.

41. Paolo Mauro. "Corruption and growth." The Quarterly Journal of Economics (1995): 681-712. [CrossRef]

42. Utz Weitzel, and Sjors Berns. "Cross-border takeovers, corruption, and related aspects of governance." Journal of International Business Studies 37 (2006): 786-806. [CrossRef]

43. Rajib Sanyal, and Subarna Samanta. "Relationship between Bribery and Economic Growth: An Empirical Analysis." Indian Journal of Economics E Business 9 (2010): 133-45.

44. Teresa Hernandez, and Robert W. McGee. "The Ethics of Accepting a Bribe: An Empirical Study of Opinion in the USA, Brazil, Germany and China." International Journal of Business, Accounting, and Finance 6 (2012): 178-96. [CrossRef]

45. Teresa Hernandez, and Robert W. McGee. "Ethical Attitudes toward Taking a Bribe: A Study of Three Latin American Countries." International Journal of Business E Economics Perspectives 8 (2013): 142-66. [CrossRef] 
46. Teresa Hernandez, and Robert W. McGee. "Attitudes towards bribery in Australia: A Demographic Study." Euro Asia Journal of Management 24 (2014): 57-91. [CrossRef]

47. Teresa Hernandez, and Robert W. McGee. "Ethical Attitudes towards taking a bribe: A Study of Four European Countries." Euro Asia Journal of Management 22 (2012): 3-28. [CrossRef]

48. Teresa Hernandez, and Robert W. McGee. "The Ethical Perceptions of Bribe Taking in Four Muslim Countries." Journal of Accounting, Ethics and Public Policy 151 (2014): 185-237.

49. Teresa Hernandez, and Robert W. McGee. "A Demographic Study of African attitudes on Bribery." Journal of Accounting, Ethics and Public Policy 15 (2014): 541-96.

50. Teresa Hernandez, and Robert W. McGee. "The Ethics of Accepting a Bribe: A Comparative Study of Opinion in the USA." Journal of Accounting, Ethics and Public Policy 14 (2013): 945-98.

51. R. Core Team. R: A Language and Environment for Statistical Computing. Vienna: R Foundation for Statistical Computing, 2010.

52. Malika Charrad, Nadia Ghazzali, Veronique Boiteau, and Azam Niknafs. "NbClust: An R Package for Determining the Relevant Number of Clusters in a Data Set." Journal of Statistical Software 61 (2014): 1-36. [CrossRef]

(C) 2017 by the authors; licensee MDPI, Basel, Switzerland. This article is an open access article distributed under the terms and conditions of the Creative Commons Attribution (CC-BY) license (http://creativecommons.org/licenses/by/4.0/). 